\title{
CORRIGENDUM
}

\section{Effects of high-dose cholecalciferol on serum markers of inflammation and immunity in patients with early chronic kidney disease}

JA Alvarez, SM Zughaier, J Law, L Hao, H Wasse, TR Ziegler and V Tangpricha

European Journal of Clinical Nutrition (2013) 67, 1228; doi:10.1038/ejcn.2013.190

Correction to: European Journal of Clinical Nutrition (2013) 67, 264-269; doi: 10.1038/ejcn.2012.217; published online 30 January 2013

Since the publication of this paper, the authors have noticed that it is incorrectly written in the methods, results, and a figure legend that human THP-1 monocytic cells were incubated with $4 \mu \mathrm{m}$ of $1,25(\mathrm{OH})_{2} \mathrm{D}_{3}$. The concentration of $1,25(\mathrm{OH})_{2} \mathrm{D}_{3}$ should read $40 \mathrm{~nm}$. This correction does not affect the conclusion that $1,25(\mathrm{OH})_{2} \mathrm{D}_{3}$ decreased MCP-1 release from THP-1 monocytes.

The authors apologize for any inconvenience caused. 